\title{
Development of an Atmosphere-Ocean-Geosphere-Coupled Model and its application to the Kanto plain, Japan
}

\author{
J.F. Vuillaume $^{\mathrm{a}}{ }^{\mathrm{e}}$, S. Fukazawa ${ }^{\mathrm{b}}$, K. Goto ${ }^{\mathrm{c}}$, A. Hazart ${ }^{\mathrm{b}}$, Y. Konishi ${ }^{\mathrm{b}}$, R. Onishi ${ }^{\mathrm{a}}$, T. Sugiyama ${ }^{\text {a }}$, \\ K. Tada ${ }^{\mathrm{b}}$, Y. Tawara ${ }^{\mathrm{b}}$, H. Tosaka ${ }^{\mathrm{b}}$ and K. Takahashi ${ }^{\mathrm{a}}$

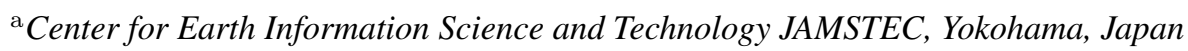 \\ ${ }^{\mathrm{b}}$ Geosphere Environmental Technology Corporation, Tokyo, Japan \\ ${ }^{\mathrm{c}}$ NEC Corporation, Tokyo, Japan \\ Email: vuillaume@jamstec.go.jp
}

\begin{abstract}
Water circulation between atmosphere and geosphere generates important feedbacks. Thus, a coupled model has been developed by combining the Multi-Scale Simulator for the Geoenvironment for Atmosphere (MSSG-A), for Ocean (MSSG-O) and the GEneral purpose Terrestrial fluid-FLOW Simulator (GETFLOWS) for surface-groundwater. The information exchange between the simulators is controlled dynamically by the OASIS coupler. The coupled model can handle short time (10min to daily), seasonal (several months to yearly) and potentially decadal (not implemented yet) water circulation. The model is used to investigate the influence of temperature, rainfall and evaporation on land surface run-off and ground water as well as soil moisture and latent heat on climate. An important application is to model the impact of future climate change and support sustainable development. The current paper focus on model description and mass-balance assessment. Some preliminary experiments were performed using a model with a $500 \mathrm{~m}$ horizontal resolution, exchanging data every 10 minutes on 147 computing cores. The model covers the whole Kanto basin in Japan and is assessed over the period 21/07/2006 to 08/09/2006 that includes one extreme rainfall event. First, the water mass balance of the coupled model was estimated by comparing the aquifer water storage (groundwater, soil moisture and river storage) computed by the hydrological model and the water flux of the watershed such as rainfall, evaporation, river discharge and coastal exchange at the land-ocean interface. The coupled model achieved good mass conservation. In a second step, the present coupled model was validated with observation data. Comparison with rainfall station data showed that the model underestimated the rainfall at high elevation locations but overestimated the rainfall at low elevation locations. Despite these biases, the overall rainfall was well reproduced by the model. Comparison with gridded satellite derived TRMM rainfall data showed that the cumulative precipitation volume modelled in the domain agrees with the satellite observation with an error of $15 \%$ or less.
\end{abstract}

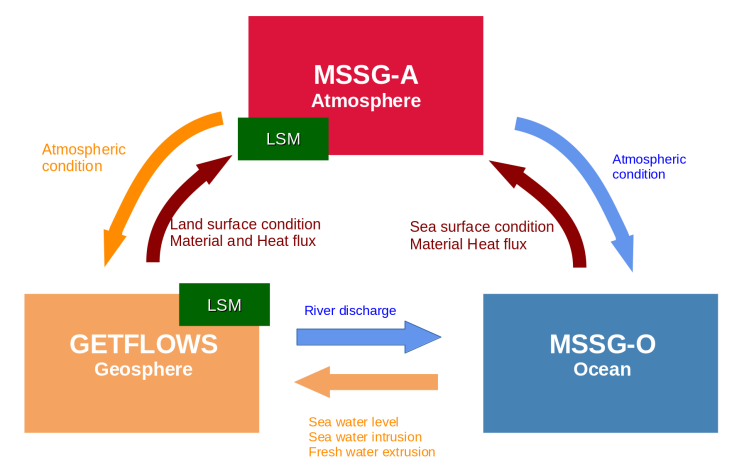

Figure 1. Schematic dynamic coupling strategy between ocean, atmosphere and geosphere model.

Keywords: Atmosphere-ocean-geosphere model, dynamical coupling, Kanto plain 


\section{INTRODUCTION}

Climate change and urbanization are impacting major cities around the world, causing increase of heat island effects and urban floods. Urban development must take greater account of those impacts, which are usually caused by highly nonlinear complex physics. It is then preferable to take a science-driven adaptation strategy, i.e., the strategy driven by scientific numerical results from physics-based models, in order to optimise urban planning decisions and to increase river restoration, groundwater recharge and green infrastructures. In this study, we developed a numerical framework that couples atmosphere, ocean, and geosphere models. The coupling takes advantage of the hydrological model, which captures soil moisture and ground temperature estimation, while the atmospheric model improves the accuracy of the Land Surface Model (LSM) with more realistic rainfall and evaporation flux.

Surface, groundwater, atmosphere and ocean models are generally developed as separate standalone models. However, water circulation research requires the modelling of the whole cycle as feedbacks exist among compartments (Davison et al., 2018). Generally, LSMs lack the critical feedbacks between surface and groundwater hydrologies (Bierkens, 2015). Moreover, Keune et al. (2016) indicated that the groundwater representation significantly impacts land surface-atmosphere processes. A study on the Southern Great Plains (USA) by Maxwell and Kollet (2008) concluded that the groundwater depth determines the relative susceptibility of changes in temperature and precipitation.

Several projects have already investigated the coupling and feedbacks of atmospheric and geosphere models (Maxwell et al., 2011; Larsen et al., 2016; Wagner et al., 2016) in different locations (US, Denmark, Germany) with various numerical models. Improvements in both hydrological and climate modelling have the capacity to produce results that represent the water cycle with greater fidelity. However, limitations remain in current coupled models. For instance, surface and subsurface systems are not fully coupled in Keune et al. (2016), the ocean is not modelled and the convective cells are not fully resolved but rather parameterized in Senatore et al. (2015). In this research, we used a geosphere model (GETFLOWS), a multi-scale atmosphere model (MSSG-A) and an ocean model (MSSG-O) to consider (1) fully coupled water flow between surface and subsurface, (2) physically modelled convection, and (3) modelled ocean level, sea water intrusion/extrusion and salt transport.

\section{DEVELOPMENT OF THE COUPLED MODEL}

The coupling is achieved using the OASIS coupler that permits (1) the exchange of atmospheric states variable and water flux through the LSM, and (2) computation of the sensible heat $\left(Q_{E}\right.$, Equation 1), latent heat $\left(Q_{H}\right.$, Equation 2), short wave radiation $\left(S_{u}\right.$, Equation 3 ) and thermal conductivity (G, Equation 4 ) with variable for both models. Moreover, the ocean model can exchange sea water level, river discharge and salinity with the geosphere module in coastal areas.

$$
\begin{aligned}
& Q_{E}=-l \rho_{a} \beta \alpha_{a}\left(q-q_{s a t}\left(T_{s}\right)\right. \\
& Q_{H}=-c_{a} \rho_{a} \alpha_{h}\left(T-T_{s}\right) \\
& S_{u}=\alpha S_{d} \\
& G=\lambda \frac{T_{g}-T_{s}}{d z}
\end{aligned}
$$

where:

1:latent heat of evaporation ( $\left.\mathrm{J} . \mathrm{Kg}^{-1}\right), \mathrm{MSSG}, \rho \mathrm{a}$ : the atmospheric density $\left(\mathrm{Kg}^{-\mathrm{m}^{-3}}\right), \mathrm{MSSG}$,

$\beta$ : evaporation efficiency (-), GETFLOWS,

q: specific humidity ( $\left.\mathrm{Kg} . \mathrm{Kg}^{-1}\right)$, MSSG,

$q_{\text {sat }}$ : specific humidity at saturation $\left(\mathrm{Kg}_{\mathrm{Kg}} \mathrm{Kg}^{-1}\right)$, GETFLOWS,

T: temperature (K), MSSG, 
$T_{g}:$ ground surface temperature $(\mathrm{K})$, GETFLOWS,

$T_{s}$ : air surface temperature $(\mathrm{K})$, GETFLOWS,

$c_{a}$ : Constant-pressure specific heat of the atmosphere $\left(\mathrm{J}^{\mathrm{kg}} \mathrm{kg}^{-1} \cdot \mathrm{K}^{-1}\right), \mathrm{MSSG}$,

$\alpha_{h}$ : bulk transport coefficient (-), MSSG,

$S_{d}$ : Downward shortwave radiation (W.m ${ }^{-2}$ ), MSSG,

$\lambda$ : Average thermal conductivity or water thermal conductivity $\left(\mathrm{W} \cdot \mathrm{m}^{-1} \cdot \mathrm{K}^{-1}\right)$, GETFLOWS,

$\mathrm{dz}$ : the vertical thickness of the soil (m), GETFLOWS.

\subsection{MSSG-O and MSSG-A: Ocean and Atmospheric modelling}

MSSG is a multiscale atmosphere-ocean coupled nonhydrostatic model for global to local scales (Takahashi et al. 2006 2013). The MSSG comprises atmosphere (MSSG-A) and ocean (MSSG-O) modules. MSSG uses a conventional long-lat grid system for regional simulations and the Yin-Yang grid system (Kageyama and Sato, 2004; Baba et al. 2010), which comprises two overlapping long-lat grids to avoid polar singularity. The MSSG-A dynamical core is based on the nonhydrostatic equations; it predicts the three wind components, air density and pressure. Each horizontal computational domain covers $550 \times 440$ grids in the Yin-Yang lat-long grid system. The average horizontal grid spacing was $510 \mathrm{~m}$ for the present test simulation .

\subsection{GETFLOWS subsurface and surface hydrology modelling}

GETFLOWS is a general-purpose terrestrial fluid-flow simulator that has been developed to model fluid flow in a comprehensive way. It uses an integral finite difference method to solve the governing equation on three dimensional corner-point grids with fully-coupled surface water and subsurface fluid flow, and distributed, dynamic land surface conditions (land use, air temperature, precipitation, water body, man-made structures (Tosaka et al., 2000, 2010; Mori et al., 2015).

\subsection{OASIS coupling and data transfer}

The OASIS coupler is a software allowing synchronized exchanges of coupling information between numerical codes representing different components of the climate system (Craig et al., 2017). The Figure 2 illustrates the coupling strategy chosen with the variable exchanged at a 10 min interval between GETFLOWS and MSSGAO through OASIS.

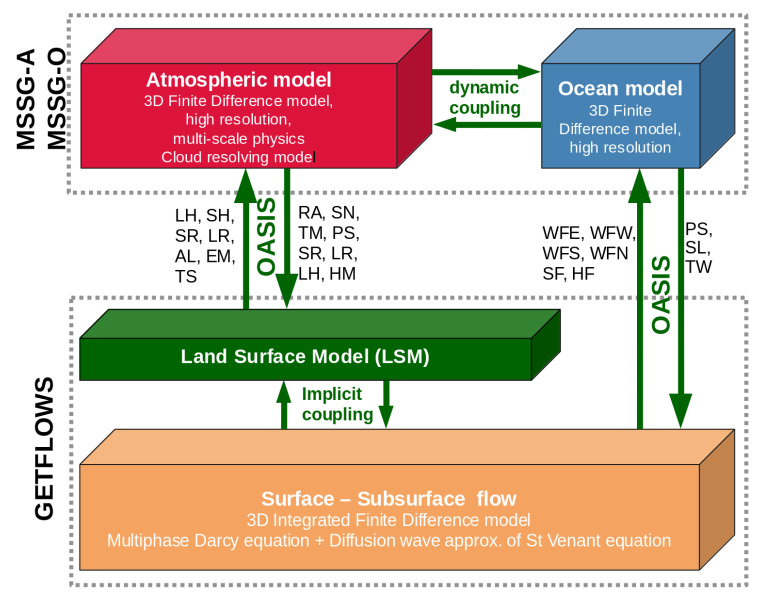

MSSG-A $\leftrightarrow$ GETFLOWS
RA: Rainfall
SN: Snowfall
TM: Atm. Temperature 1L
PS: Atm. Pressure
SR: Down. Sw Rad.
LR: Down. Lw rad.
LH: :atent Heat
SH: Sensible Heat
HM: Atm. Humidity 1 L
AL: Albedo
EM: Injection Rate
TS: Air Surf. Temp.
TG: Ground Surf. Temp
MSSG-O $\leftrightarrow$ GETFLOWS
MS: Water Pressure
SL: Salt Concentration
TW: Water Temperature
WFE, WFW, WFS, WFN: Water Transfer
SF: Salt Transfer
HF: Heat Transfer

Figure 2. Coupling schematics. 


\section{MODEL APPLICATION}

\subsection{Overview of the Kanto plain}

The Kanto plain area is an intensively urbanized area $(\approx 40$ million people) that encompassed Chiba, Ibaraki, Guma, Tochigi, Saitama, Tokyo and Kanagawa prefectures. It consists of a flat plain, with mountainous parts in the north and west, and coastlines in the east and south that faces the Pacific Ocean. The sedimentary deposit of the aquifer was formed by a sub-marine basin with 2500-3000 m thick sediment from Miocene to Holocene age that constraints both it geometry and sedimentary deposits properties and the aquifer limits are well known. In early 1970s, massive groundwater over-pumping use for industrial development led to serious problems of subsidence (Furuno et al., 2015). A 3D geomodel was developed for the Kanto aquifer that described the geometry of the basement, the Miura, Kazusa and Shimofusa deposit group with specific porosity and permeability properties taken from literature (Figure 4).

\subsection{Model setup}

A 3D geomodel was developed for the Kanto aquifer that described the geometry of the impermable basement, the Miura, Kazusa and Shimofusa deposit group with specific porosity and permeability properties taken from references (Figure 3). The Kanto plain and atmospheric simulation domains are illustrated in Figure 4. The Kanto plain area is considered as the domain of data exchange through OASIS (Figure 5). The geosphere is discretized over a grid of $550 \times 440 \times 42$ gridblocks and the atmospheric model over a grid of $550 \times 440 \times$ 32 gridblocks
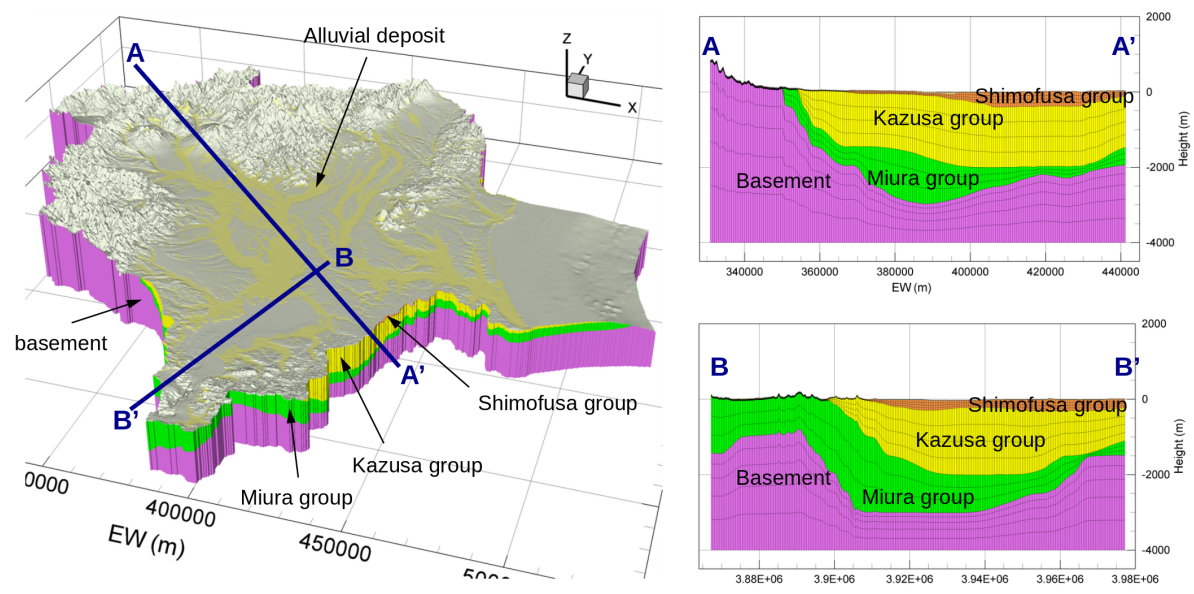

Figure 3. 3D geomodel and 2D cross sections of the Kanto plain.

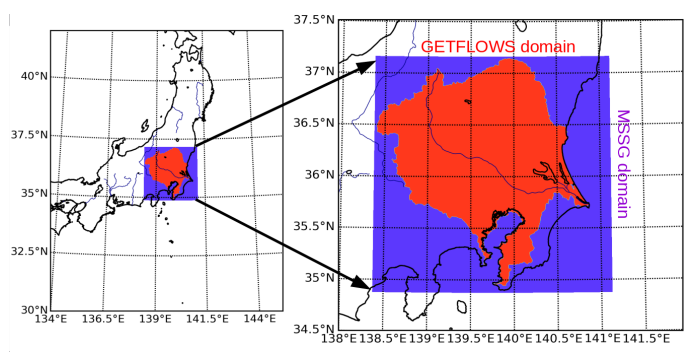

Figure 4. Location of the Kanto plain and representation of the model domain.

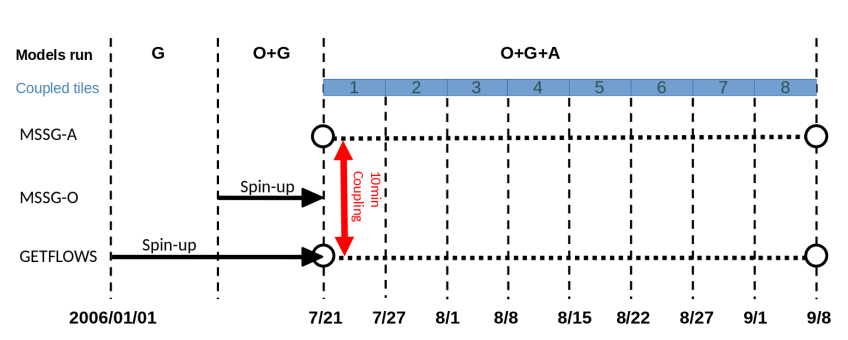

Figure 5. Model coupling and spin-up. 
First, the GETFLOWS model run from 01/01/2006 after about 100000 years of initialization in order to produce a water table level in quasi-equilibrium. Then, it run 100 years as standalone model using MSSG-A static inputs. Following that, the MSSG-Ocean start the 01/07/2006 to produce realistic sea surface temperatures. Finally the MSSG-Atmospshere start from 21/07/2006. The spin-up period of the coupled model is estimated to 5-10 days. Moreover, computer resource limitations required restart periods on average every 6 days.

\subsection{Simulated results}

Mass balance. The water mass balance is estimated using the equation 5. The storage change (dS) was estimated with GETFLOWS model, the rainfall (Ra) and evaporation (E) were computed by the MSSG-A model while river discharge and sea intrusion are estimated through OASIS.

$$
\Delta S=R a-E-R i v+S i
$$

where: $\Delta \mathrm{S}$ : The aquifer storage volume change estimated by GETFLOWS

Ra: The cumulative rainfall volume computed by MSSG-A

Riv: The cumulative river discharges computed by GETFLOWS

$\mathrm{Si}$ : The cumulative coastal sea water intrusion computed by GETFLOWS/MSSG-O

The mass balance is estimated to $3.4 \%$ difference between the aquifer storage change and the water flux. The difference between flux and storage is further illustrated in Figure 7. While the storage and the sum of the flux suggests a "good" fit, it indicates that the divergence occurs mainly after rainfall events, during the evaporation period. In addition, the total cumulative infiltration is indicated.

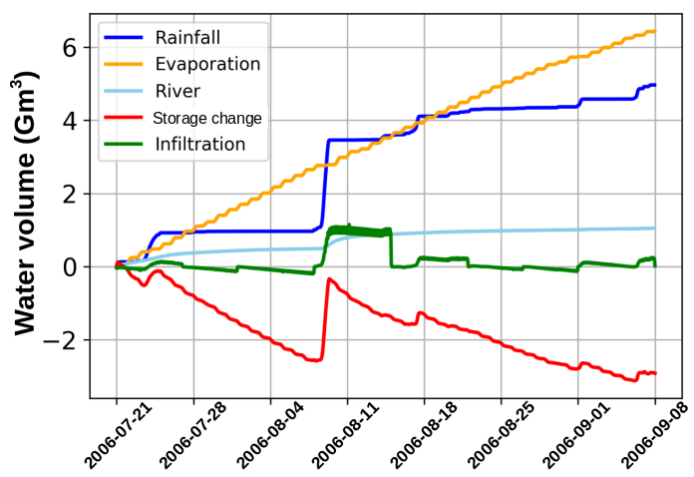

Figure 6. Cumulative water flux over the period 27/07/2006-08/09/2006.

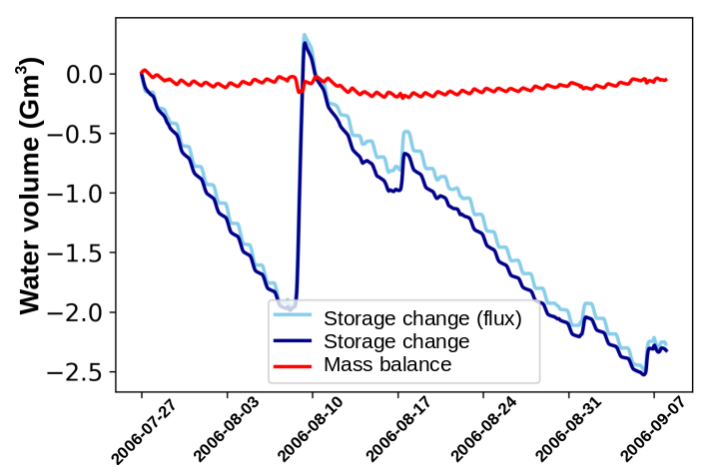

Figure 7. Cumulative water mass computed by the groundwater model (dark blue line), the sum of the flux (sky blue line) and their difference (red line) for the 27/07/2006-08/09/2006.

Rainfall and groundwater water level. The cumulative rainfall and groundwater level change for each simulated period is shown in Figure 8. The aquifer responded to rainfall events. Ground water levels increased due to the wet period (08/08/2006-15/08/2006) and decreased due to the dry period (27/08/2006-31/08/2006). A comparison between the modelled cumulative rainfall and satellite rainfall from the Tropical Rainfall Measuring Mission (TRMM) indicated that the model overestimates satellite derived rainfall by $15 \%$ (Figure 9).

The Figure 10 illustrates the rainfall distribution observed by the Automated Meteorological Data Acquisition System (AMEDAS) rain gauge station network, the coupled model estimation at similar locations (virtual station), the difference between modelled and observed values and, the relative cumulative rainfall difference as a percentage. The main limitations of the model are located in mountain areas where rainfall is strongly underestimated (North-West part). In contrast, the Kanto area rainfall is overestimated in the central region by MSSG-A. 


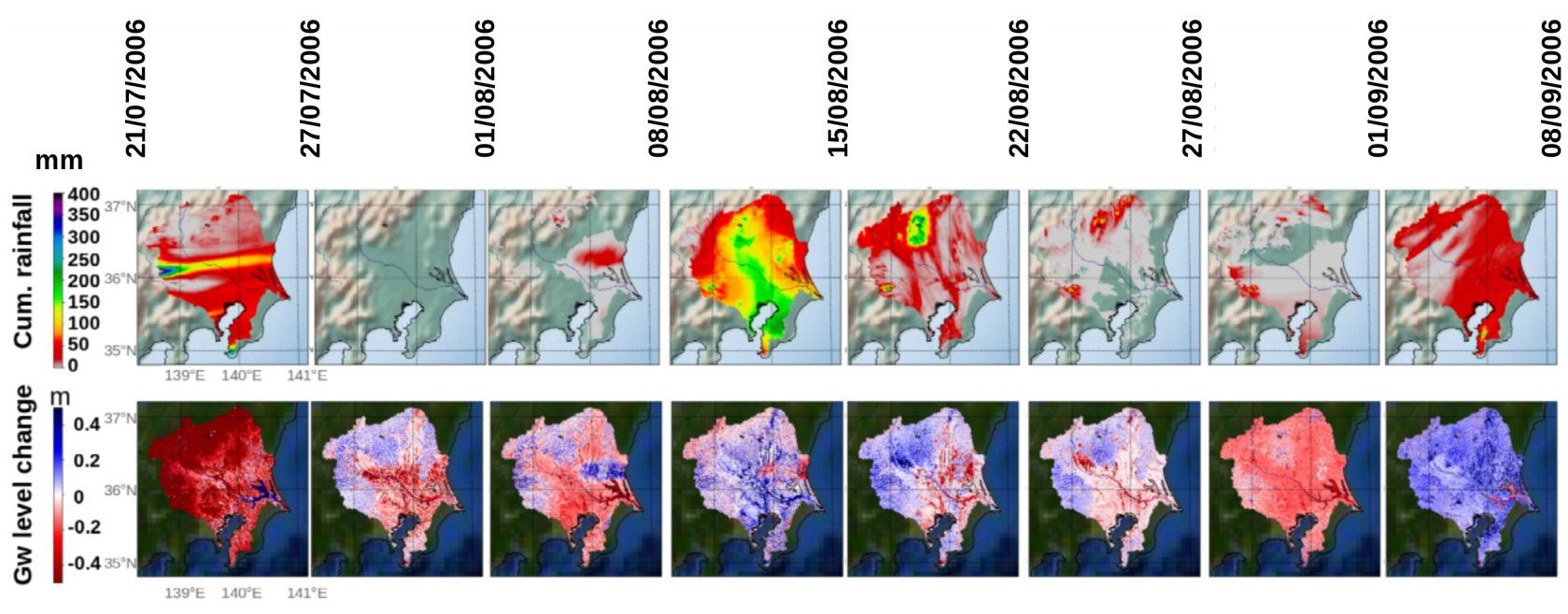

Figure 8. Cumulative rainfall and groundwater level change per restart tiles over the period 27/07/200608/09/2006.
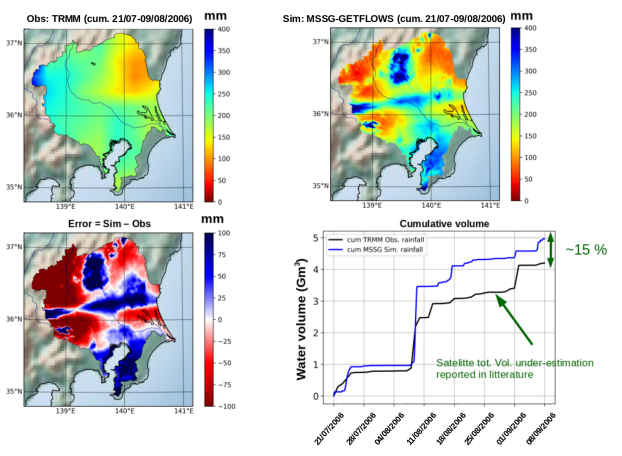

Figure 9. Cumulative rainfall distribution from TRMM satellite data (Top-Left) and from the present coupled model(Top-Right). Cumulative rainfall "Model - Obs" (Bottom-Left). The time series of the cumulative rainfall (Bottom-Right) Cumulative volume time series.
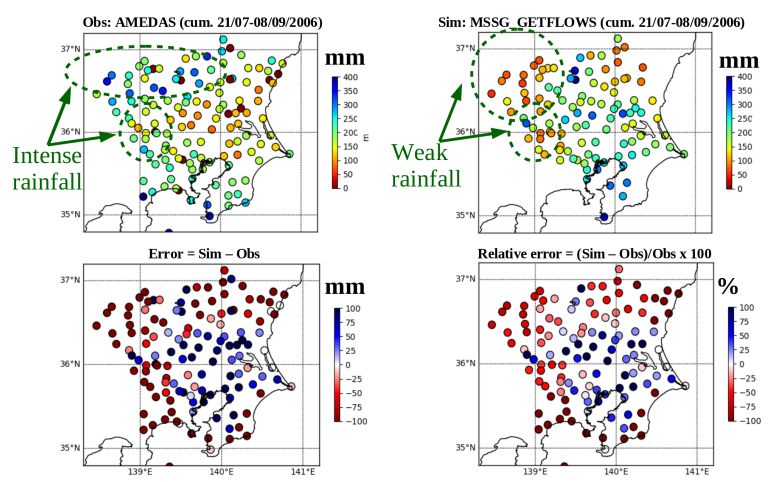

Figure 10. AMEDAS cumulative raingauge validation (Top-Left) Cumulative coupled model virtual rainfall station (Top-Rigth) (Bottom Left) "Model - Obs" stations (Bottom-Rigth) Relative error.

\section{Conclusion}

This paper described the development of a dynamical Atmosphere-Ocean-Geosphere-Coupled Climate Model and its application to the Kanto plain in Japan. The model can be used to (1) investigate feedback of both land surface and groundwater on rainfall and evaporation (2) provide information for sustainable development of the Kanto plain and will be used to (3) consider the impact of future climate change in the Kanto area. The present coupled model showed acceptable mass balance error $(\approx 3.4 \%)$ and promising rainfall volume modelling $(15 \%$ cumulative mass difference compare to TRMM data). The discrepancy in the rainfall distribution in the current configuration generates a shift in the discharge peak flow of rivers. The present model underestimated rainfall at high altitude (North-West) and overestimated rainfall in the Kanto plain area. Future work will be dedicated to (1) the analysis of the groundwater level change,(2) the use dynamical downscaling of the atmospheric model to improve rainfall modelling in high altitude regions and (3) quantitative assessment of uncoupled models for a similar period and domain. 


\section{ACKNOWLEDGEMENT}

This work was supported by JST COI Grant Number JPMJCE1316. The authors acknowledge contributions from all the members of the COI-STREAM project. Two anonymous reviewers provided helpful comments on earlier drafts of the manuscript.

\section{REFERENCES}

Baba, Y., K. Takahashi, T. Sugimura, and K. Goto (2010). Dynamical core of an atmospheric general circulation model on a yin-yang grid. Monthly Weather Review 138(10), 3988-4005.

Bierkens, M. F. P. (2015). Global hydrology 2015: State, trends, and directions. Water Resources Research 51(7), 4923-4947.

Craig, A., S. Valcke, and L. Coquart (2017). Development and performance of a new version of the oasis coupler, oasis3-mct_3.0. Geoscientific Model Development 10(9), 3297-3308.

Davison, J. H., H.-T. Hwang, E. A. Sudicky, D. V. Mallia, and J. C. Lin (2018). Full coupling between the atmosphere, surface, and subsurface for integrated hydrologic simulation. Journal of Advances in Modeling Earth Systems 10(1), 43-53.

Furuno, K., A. Kagawa, O. Kazaoka, T. Kusuda, and H. Nirei (2015). Groundwater management based on monitoring of land subsidence and groundwater levels in the kanto groundwater basin, central japan. Proceedings of the International Association of Hydrological Sciences 372, 53-57.

Kageyama, A. and T. Sato (2004). "yin-yang grid": An overset grid in spherical geometry. Geochemistry, Geophysics, Geosystems 5(9).

Keune, J., F. Gasper, K. Goergen, A. Hense, P. Shrestha, M. Sulis, and S. Kollet (2016). Studying the influence of groundwater representations on land surface-atmosphere feedbacks during the european heat wave in 2003. Journal of Geophysical Research: Atmospheres 121(22), 13,301-13,325.

Larsen, M. A. D., S. H. Rasmussen, M. Drews, M. B. Butts, J. H. Christensen, and J. C. Refsgaard (2016, Jan). Assessing the influence of groundwater and land surface scheme in the modelling of land surfaceatmosphere feedbacks over the fife area in kansas, usa. Environmental Earth Sciences 75(2), 130.

Maxwell, R. and S. Kollet (2008). Interdependence of groundwater dynamics and land-energy feedbacks under climate change. Nature Geoscience 1, 665-669.

Maxwell, R. M., J. K. Lundquist, J. D. Mirocha, S. G. Smith, C. S. Woodward, and A. F. B. Tompson (2011). Development of a coupled groundwater-atmosphere model. Monthly Weather Review 139(1), 96-116.

Mori, K., K. Tada, Y. Tawara, K. Ohno, M. Asami, K. Kosaka, and H. Tosaka (2015). Integrated watershed modeling for simulation of spatiotemporal redistribution of post-fallout radionuclides: Application in radiocesium fate and transport processes derived from the fukushima accidents. Environmental Modelling and Software 72, $126-146$.

Senatore, A., G. Mendicino, D. J. Gochis, W. Yu, D. N. Yates, and H. Kunstmann (2015). Fully coupled atmosphere-hydrology simulations for the central mediterranean: Impact of enhanced hydrological parameterization for short and long time scales. Journal of Advances in Modeling Earth Systems 7(4), 1693-1715.

Takahashi, K., R. Onishi, Y. Baba, S. Kida, K. Matsuda, K. Goto, and H. Fuchigami (2013, aug). Challenge toward the prediction of typhoon behaviour and down pour. Journal of Physics: Conference Series 454, 012072.

Takahashi, K., X. Peng, R. Onishi, M. Ohdaira, K. Goto, H. Fuchigami, and T. Sugimura (2006). Multi-scale coupled atmosphere-ocean $\mathrm{gcm}$ and simulations. 12th, high performance computing, hpc, workshop.

Tosaka, H., K. Itoh, and T. Furuno (2000). Fully coupled formulation of surface flow with 2-phase subsurface flow for hydrological simulation. Hydrological Processes 14(3), 449-464.

Tosaka, H., K. Mori, K. Tada, Y. Tawara, and K. Yamashita (2010). A general-purpose terrestrial fluids/heat flow simulator for watershed system management. iahr international groundwater symposium.

Wagner, S., B. Fersch, F. Yuan, Z. Yu, and H. Kunstmann (2016). Fully coupled atmospheric-hydrological modeling at regional and long-term scales: Development, application, and analysis of wrf-hms. Water Resources Research 52(4), 3187-3211. 